\title{
Clinical Characteristics of Chronic Hepatitis B Virus Infection in Immigrants from Sub-Saharan Africa
}

\author{
Hatef Massoumi, ${ }^{1,}{ }^{*}$ Kathleen Buchheit, ${ }^{2}$ Srinivas Gunturu, ${ }^{2}$ Ju-En Thlick, ${ }^{2}$ and Paul Gaglio ${ }^{2}$ \\ ${ }^{1}$ New York Associates in Gastroenterology, Montefiore Medical Center, Bronx, New York \\ ${ }^{2}$ MD Montefiore Medical Center, Bronx, New York \\ "Corresponding author: Hatef Massoumi, New York Associates in Gastroenterology, Montefiore Medical Center, Bronx, New York. E-mail: hamassou@montefiore.org
}

Received 2016 August 25; Revised 2016 October 26; Accepted 2016 October 28.

\begin{abstract}
Chronic hepatitis B virus (HBV) infection is a significant, worldwide burden due to it's high prevalence, and risk of complications, including cirrhosis and hepatocellular carcinoma (HCC). Current literature suggests that African patients with chronic hepatitis B are at higher risk for hepatocellular carcinoma. The exact mechanism for the explanation for this observation is contentious and may be due to higher rates of chronicity, and/or exposure to hepatotoxins including aflatoxin. We sought to report the clinical characteristics of African born immigrants with chronic hepatitis B referred to a liver clinic in New York City. A total of 111 patients were enrolled. 19 patients (17\%) had cirrhosis, and 14 patients (13\%) had HCC at initial presentation. During the course of follow up, 13 patients (12\%) died of complications of HBV, all of them related to HCC. Our case series revealed that a significant proportion of these patients manifested advanced complications of HBV such as cirrhosis or HCC.
\end{abstract}

Keywords: Hepatitis B, Hepatoma, Genotype E, Sub-Saharan Africans

\section{Background}

Chronic hepatitis B virus (HBV) infection is a significant, worldwide burden due to it's high prevalence, and significant risk of complications, including cirrhosis and hepatocellular carcinoma (HCC). While it is difficult to determine the true international burden of chronic HBV infection given underreporting and lack of required screening, most recent estimates by the world health organization (WHO) report that worldwide, 2 billion people have been exposed and 378 million persons ( $6 \%$ of world population) are chronically infected. In addition, the prevalence of HBV is highest in patients born in Africa and Asia1, and rates of advanced liver disease including cirrhosis and HCC are highest in these regions $(1,2)$. At present, the majority of data related to HCC and advanced liver disease in patients born in Africa are derived from observational studies conducted in that country. However, there is a paucity of data related to the natural history of HBV in African born patients who live in the USA.

\section{Objectives}

Our study was conducted to evaluate the clinical characteristics of patients with chronic HBV infection who have emigrated from Africa.

\section{Methods}

The Study protocol was reviewed and approved by institutional review board (IRB) of Albert Einstein College of medicine. We reviewed the records of all of our patients with chronic hepatitis B virus (HBV) infection who were treated in the liver clinic and faculty practices of Montefiore medical center and New York associates in gastroenterology. Patients with documented HBV who were born in sub-Saharan Africa were included in this study. Data was collected for a period of 10 years from 2002 to 2012. Multiple demographic and clinical factors were compiled including age, gender, degree of fibrosis, presence of HCC, hepatitis B e antigen and antibody status, HBV genotype and viral load, liver enzymes, platelet count, response to treatment, and radiographic studies. Patients were referred to the liver clinic and faculty practice by Montefiore medical center and community primary care physicians and gastroenterologists, or were followed by our practice following identification of HBV during a hospitalization. Patients were identified as African origin based on selfreporting on an initial visit questionnaire. HBV treatment candidacy was assessed based on the American Association for the study of liver diseases (AASLD) guideline (3).

Data analysis was done using Chi-square and student t-test using Graph Pad, at Graphpad.com.

\section{Results}

A total of 111 patients with a mean age of $65.6 \pm 11.2$ (SD) were enrolled. Table 1 summarizes the patient's basic characteristics. 73 male and 38 female patients were included. Hepatitis B e antigen was negative in 96 (86\%) and hepatitis B viral load was less than $2000 \mathrm{IU} / \mathrm{ml}$ in 44 (40\%), 2000 
- $20000 \mathrm{IU} / \mathrm{mL}$ in 25 (22\%) and greater than $20000 \mathrm{IU} / \mathrm{mL}$ in $28(25 \%)$ patients. The baseline HBV viral load was not able to be determined in 14 (13\%) of patients. Concurrent infection with hepatitis C or HIV was seen in $2(1.8 \%)$ and 18 (16.5\%) patients respectively. The extent of HBV disease was assessed based on a combination of patient's clinical characteristics including imaging, laboratory, and histologic assessment indicative of advanced fibrosis and cirrhosis. A total of 19 (17\%) of patients had cirrhosis at initial presentation, 7 (6\%) patients had liver biopsy and 12 (11\%) patient had imaging diagnostic of cirrhosis. Based on AASLD criteria for management of patients with chronic HBV, 61 (56\%) patients met criteria to receive anti-HBV medications. Entecavir, Tenofovir or Tenofovir-Emtricitabine were used and all patients who received anti-HBV therapy had an undetectable viral load while on therapy. No viral breakthrough was seen in this cohort. Hepatocellular carcinoma (HCC) was detected in 14 (12.8\%) patients at the time of initial presentation. Patients with HCC (mean age $57.7 \pm 14.6$ (SD)) were younger than those without HCC (mean age $66.9 \pm$ 10.0 (SD) yrs.) $(\mathrm{P}=0.0365)$. Among patients with HCC, 13 (93\%) had tumor beyond T2 Milan criteria, had tumor portal vein thrombosis or extrahepatic disease and were not candidates for resection or liver transplantation. During the course of follow up, 13 (12\%) patients died of complications of HBV, all of them related to HCC.

Table 1. Patient's Basic Characteristics

\begin{tabular}{lc}
\hline Variable & Number $(\%)$ \\
\hline Total No. of subjects & 111 \\
\hline Male & $73(66)$ \\
\hline Female & $38(34)$ \\
\hline Mean age & $65.6 \pm 11.2$ \\
\hline HBeAg negative & $96(86)$ \\
\hline HBV viral load, $<\mathbf{2 0 0 0} \mathbf{I U} / \mathbf{m L}$ & $58(52)$ \\
\hline HBV viral load, $>\mathbf{2 0 , 0 0 0} \mathbf{~ I U} / \mathbf{m L}$ & $28(25)$ \\
\hline Co-infection with HCV & $2(1.8)$ \\
\hline Co-infection with HIV & $18(16.5)$ \\
\hline Cirrhosis at presentation & $19(17)$ \\
\hline HCC at presentation & $14(12.8)$ \\
\hline
\end{tabular}

\section{Discussion}

HBV has a significant global prevalence, with highest rates ,in China, South-east Asia, most of Africa, the Pacific Islands, parts of the Middle East, and the Amazon Basin, with reported rates as high as $8 \%-15 \% .45 \%$ of all HBV infected individuals live in these regions where the lifetime risk of infection is more than 60\% (4). In Africa, the estimated prevalence of a positive hepatitis B surface antigen (HBsAg) indicating chronic $\mathrm{HBV}$ ranges from $5 \%$ to $20 \%$, with the total number of patients approaching 40 to 58 million. The exact prevalence of hepatitis B infection in the United States is not known, however reports suggested a wide range of 700000 to 2.2 million (4). As the US represents a destination for many immigrants with $\mathrm{HBV}$, the number of foreign born individuals with chronic hepatitis $\mathrm{B}(\mathrm{CHB})$ who live in the U.S. is estimated to be 1.32 million, with $11 \%$ born in Africa. A recent review of data from U.S. refugee health coordinators revealed a prevalence of $8.1 \%$ in patients born in Africa (5).

A recent meta-analysis revealed that the incidence of chronic HBV infection and mortality rates of HCC in North America and Western Europe have increased, related to high rates of undetected chronic HBV in migrants. Compared to host populations, immigrants also have a higher incidence of HCC and associated mortality (6).

Liver cancer is among the most common malignancies in several countries of West Africa (e.g., Gambia, Senegal, Mali, and Guinea), representing a quarter or more of all cancer cases. Similarly, in central Africa, liver cancer is the most common cancer in Cameroon and in the Democratic Republic of Congo (where the estimated incidence is 30 cases per 105 males and 16 per 105 females) (7).

Our institution is located in the Bronx borough of New York City with a large population of African immigrants. Most HBV infected African patients seen in our clinics are from central and West Africa. An analysis of this patient population reveals a high risk of hepatic complications such as cirrhosis (17\%) or hepatocellular carcinoma (13\%) at the time of initial presentation. We have also encountered a high rate of advanced cancer with more than $90 \%$ of tumors without curable options including resection or liver transplantation. Our analysis indicates that there are similar rates of advanced HBV and liver cancer in African immigrants living in the US. This could be partially explained by lack of awareness and proper access to health care among the African community, however; our observations parallel those in the literature that suggest a more advanced clinical presentation of HBV infection in Africa compared to Asia or Latin America. It has been reported that cancer presents at a younger age in Africans than it does in the populations of industrialized countries, and male preponderance is more common (8-10).

When assessing HBV in African born patients, it has been suggested that hepatoma occurs more commonly in individuals who were rural-born compared to those born in urban areas. Although the overall prognosis of HCC 
is poor worldwide, it is dramatically worse in African patients, with an annual tumor related fatality ratio of 0.97 (11). Our study results parallel these previously described findings. One striking finding in our cohort is that the patients with hepatoma were younger than those without. This observation is difficult to explain, but could be related to diminished access to health care for younger patients. HBV Viral genotype assessment was available for 26 patients of whom, 25 had genotype E and one with genotype A. Previous reports have suggested that genotype E is the common genotype in West and Central Africa, while genotype $\mathrm{D}$ and genotype A are more common in Northern and Southern Africa respectively. Mulders et al. studied the viral DNA of patients with genotype $\mathrm{E}$ hepatitis B in West Africa and found a very low HBV genetic diversity suggestive of "short evolutionary history" of HBV. This may indicate that the transmission and spread of HBV virus across West Africa might have happened during a relatively short period of time and is likely related to widespread use of infected needles or unsterilized medical and dental equipment in this part of the world $(12,13)$.

Several attributes of HBV in patients born in Africa might explain the observed advanced rates of cirrhosis and HCC. In a study by Moore et al. (14), the incidence and etiology of HCC in South African children were investigated. Two thirds of patients with HCC were positive for HBsAg and HCC occurred most commonly in black African patients (93\%). There was a preponderance of males (3.5: 1.0) noted in the HBsAg positive group, which was also observed in the adult population. Compared to Chinese patients with similar HBsAg prevalence, their development of HCC occurs later than Africans. It has been postulated that additional factors such as environmental exposure contribute to the development of HCC in patients born in Africa. Aflatoxin exposure, which is more common in rural Africa, is a potential environmental factor that may influence the natural history of HBV. A specific aflatoxin B1 may induce a mutation that causes inactivation of the p53 tumor suppressor gene, producing a synergistic interaction between the carcinogenic effects of chronic HBV infection and aflatoxin B1 exposure in the development of tumor of Africans (15).

Several viral factors may also explain our observations. Viana et al. (15) studied a large group of HBV infected patients with and without hepatoma. . Patient with cancer exhibited higher viral load despite relatively infrequent e antigen positive patients.

In addition, mutations in the beta catenin gene, including stabilizing mutations in exon 3 , have been found to contibute to the pathogenesis of certain human tumors, including HCC. These mutations have been found in as many as $62 \%$ of HCCs in Chinese, Japanese, and European populations. Possible interactions between the 249 serine p53 gene mutation and HBV infection have been implicated in the development of HCC; however, a clear relationship could not be established between these mutation and hepatoma in South African children (16). The potential role of core promoter mutations that are associated with greater rates of HCC such as the T1653 mutation in the enhancer II region of hepatitis B genome have been studied in South African blacks with hepatoma; however a clear relationship between these mutations and HCC could not be found (17).

Our study provides evidence that hepatitis B infection carries a significant risk for advanced liver disease and HCC in sub Saharan Africa born patients who live in the United States. The high rate of both cirrhosis and nonresectable liver cancer at presentation suggest that foreign born African patients should be screened for HBV and HCC. It could also be argued that the high rates of advanced liver disease and HCC in this patient population may require a more liberal treatment paradigm, potentially including therapy in patients outside of "standard" treatment criteria as has been proposed in the Asian American HBV treatment guidelines (18). Further prospective studies are required to further understand the natural history of HBV in foreign born African patients. We would like to acknowledge our study's limitations including the retrospective nature of our data collection, and the inability to accurately assess family history of liver cancer, as patients often did not remember their relative's medical history. In addition, HBV genotype and mutation studies were not available for all patients. Nevertheless, we believe that our observation of more advanced manifestations of HBV in this foreign born US patient population requires further analysis in a multi-centered study.

\section{Acknowledgments}

Dr. Hatef Massoumi is a member of advisory and speaker panel for Gilead Science Dr. Paul Gaglio is a member of advisory and speaker panel for Gilead science.

\section{Footnote}

Authors' Contribution: Dr. Hatef Massoumi participated in the planning of the study, collection and interpretation of data and drafting the manuscript. He is a hepatology attending at New York associates in gastroenterology and Montefiore medical center. Dr. Kathleen Buchheit participated in the planning of the study and collection of data. She was a medical student at Albert Einstein College of 
medicine. Dr. Srinivas Gunturu participated in the analysis of data and drafting of the manuscript. He was a gastroenterology fellow at Montefiore medical center. Dr. JuEn Thlick participated in the planning of the study and collection of data. He was a medical student at Albert Einstein College of medicine. Dr. Paul Gaglio participated in drafting the manuscript and interpretation of data. He is a hepatology attending at New York Presbyterian medical center. He was an attending physician at Montefiore medical center at the time of manuscript preparation.

\section{References}

1. Ioannou GN. Hepatitis B virus in the United States: infection, exposure, and immunity rates in a nationally representative survey. Ann Intern Med. 2011;154(5):319-28. doi:10.7326/0003-4819-154-5-20110301000006. [PubMed: 21357909].

2. Kowdley KV, Wang CC, Welch S, Roberts H, Brosgart CL. Prevalence of chronic hepatitis B among foreign-born persons living in the United States by country of origin. Hepatology. 2012;56(2):422-33. doi: 10.1002/hep.24804. [PubMed: 22105832].

3. Lok AS, McMahon BJ. Chronic hepatitis B. Hepatology. 2007;45(2):50739. doi: 10.1002/hep.21513. [PubMed: 17256718].

4. Te HS, Jensen DM. Epidemiology of hepatitis B and C viruses: a global overview. Clin Liver Dis. 2010;14(1):1-21. doi: 10.1016/j.cld.2009.11.009. [PubMed: 20123436] vii.

5. Rein DB, Lesesne SB, O'Fallon A, Weinbaum CM. Prevalence of hepatitis B surface antigen among refugees entering the United States between 2006 and 2008. Hepatology. 2010;51(2):431-4. doi: 10.1002/hep.23353. [PubMed: 19902482].

6. Rossi C, Shrier I, Marshall L, Cnossen S, Schwartzman K, Klein MB, et al. Seroprevalence of chronic hepatitis $B$ virus infection and prior immunity in immigrants and refugees: a systematic review and metaanalysis. PLoS One. 2012;7(9):44611. doi: 10.1371/journal.pone.0044611. [PubMed: 22957088].

7. Parkin DM, Bray F, Ferlay J, Pisani P. Global cancer statistics, 2002. CA Cancer J Clin. 2005;55(2):74-108. doi: 10.3322/canjclin.55.2.74. [PubMed: 15761078].

8. Moore SW, Millar AJ, Hadley GP, Ionescu G, Kruger M, Poole J, et al. Hepatocellular carcinoma and liver tumors in South African chil- dren: a case for increased prevalence. Cancer. 2004;101(3):642-9. doi: 10.1002/cncr.20398. [PubMed: 15274079].

9. Kirk GD, Bah E, Montesano R. Molecular epidemiology of human liver cancer: insights into etiology, pathogenesis and prevention from The Gambia, West Africa. Carcinogenesis. 2006;27(10):2070-82. doi: 10.1093/carcin/bgl060. [PubMed: 16679307].

10. Widjaja D, Yarlagadda S, Singu BS, Loganathan RS, Blum S, Bloom A, et al. Characteristics of patients with chronic hepatitis-B virus infection in an urban hospital. J Natl Med Assoc. 2007;99(4):384-8. [PubMed: 17444427].

11. Kew MC. Hepatocellular carcinoma in African Blacks: Recent progress in etiology and pathogenesis. World J Hepatol. 2010;2(2):65-73. doi: 10.4254/wjh.v2.i2.65. [PubMed: 21160975].

12. Kramvis A, Kew MC. Epidemiology of hepatitis B virus in Africa, its genotypes and clinical associations of genotypes. Hepatol Res. 2007;37(1):9-19.

13. Mulders MN, Venard V, Njayou M, Edorh AP, Bola Oyefolu AO, Kehinde MO, et al. Low genetic diversity despite hyperendemicity of hepatitis B virus genotype E throughout West Africa. J Infect Dis. 2004;190(2):400-8. doi: 10.1086/421502. [PubMed: 15216479].

14. Moore SW, Davidson A, Hadley GP, Kruger M, Poole J, Stones D, et al. Malignant liver tumors in South African children: a national audit. World J Surg. 2008;32(7):1389-95. doi: 10.1007/s00268-008-9526-8. [PubMed: 18305988].

15. Viana R, Wang R, Yu MC, Welschinger R, Chen CY, Kew MC. Hepatitis $B$ viral loads in southern African Blacks with hepatocellular carcinoma. J Med Virol. 2009;81(9):1525-30. doi: 10.1002/jmv.21574. [PubMed: 19623667].

16. Elmileik H, Paterson AC, Kew MC. Beta-catenin mutations and expression, 249serine p53 tumor suppressor gene mutation, and hepatitis B virus infection in southern African Blacks with hepatocellular carcinoma. J Surg Oncol. 2005;91(4):258-63. doi: 10.1002/jso.20304. [PubMed: 16121349].

17. Welschinger R, Kew MC, Viana R, Badri M. T1653 mutation in the enhancer II region of the hepatitis $B$ virus genome in southern African Blacks with hepatocellular carcinoma. Eur J Gastroenterol Hepatol. 2010;22(5):541-5. doi: 10.1097/MEG.ob013e3283344991. [PubMed: 20173647].

18. Tong MJ, Hsu L, Chang PW, Blatt LM. Evaluation of current treatment recommendations for chronic hepatitis B: a 2011 update. J Gastroenterol Hepatol. 2011;26(5):829-35. doi: 10.1111/j.1440-1746.2011.06623.x. [PubMed: 21214888]. 